\title{
DIFERENTES PAISAJES Y ANÁLOGAS REPRESENTACIONES. INTERPRETACIÓN ARQUEOLÓGICA CON TECNOLOGÍAS DE INGENIERÍA INVERSA
}

\section{DIFFERENT LANDSCAPES AND ANALOGS REPRESENTATIONS. ARCHAEOLOGICAL INTERPRETATION WITH INVERSE ENGINEERING TECHNOLOGIES}

\author{
Xosefina Otero ${ }^{a,}{ }^{*}$, Mercedes Farjas $^{a}$, Manuel Santos $^{b}$, Jorge Angás ${ }^{c}$ \\ ${ }^{a}$ ETS de Ingenieros en Topografía, Cartografía y Geodesia, Universidad Politécnica de Madrid, Campus Sur- UPM Crta. de Valencia \\ km 7, 28031 Madrid, España. artabria@gmail.com, m.farias@upm.es \\ ${ }^{\mathrm{b}}$ Lab2Pt Universidade do Minho, Braga, Portugal, manuel.santos@mundo-r.com \\ ${ }^{c}$ 3DScannerTechnologies, Avenida de Navarra 103, Zaragoza administrador@3dscanner.es
}

\begin{abstract}
:
In this paper we present new methods of the documentation and registration of the petroglyphs of the exceptional archaeological site located on Khor Fakkan, emirate of Sharjah, on the east coast of the United Arab Emirates along the Gulf of Oman, and coordinates $24^{\circ} 59^{\prime} 06.06^{\prime \prime} \mathrm{N}-56^{\circ} 20^{\prime} 36.70^{\prime \prime} \mathrm{E}$. The engravings on the surface of the serpentine rock fragments, of the Semail ophiolite complex that was generated when the Saudi plate was introduced under the IranZagros, in the Cretaceous, are made with the technique and striped characteristic of the Bronze Age and Iron Age. We conducted the study respecting its conservation without any intervention on them, using the latest available technologies and performing aerial, terrestrial and near object digital photogrammetry and applying at the same time the methodology of Landscape Archaeology.
\end{abstract}

Key words: Petroglyphs, Bronze Age, Iron Age, Aerial, terrestrial and near object digital photogrammetry, Landscape Archaeology.

\section{Resumen:}

En este artículo presentamos nuevos métodos de documentación y registro de los petroglifos de un sitio arqueológico excepcional localizado en Khor Fakkan, en el Emirato de Sharjah, en la costa este de los Emiratos Árabes Unidos, a lo largo del Golfo de Omán y cuyas coordenadas geográficas son 2459'06.06" N - 56²0'36.70" E. Los grabados, en la superficie de fragmentos de roca serpentina del complejo ofiolítico Semail, que fue generado cuando la placa Saudí se introdujo bajo la Irán-Zagros, durante el Cretácico, se realizaron con técnicas y estilos propios de la Edad del Bronce y del Hierro. Llevamos a cabo su estudio respetando su perfecta conservación y sin ningún tipo de intervención sobre ellos, utilizando las últimas tecnologías disponibles y realizando fotogrametría digital aérea, terrestre y de objeto cercano, y aplicando, a la vez, la metodología de la arqueología del paisaje.

Palabras clave: Petroglifos, Edad de Bronce, Edad de Hierro, Fotogrametría digital aérea, terrestre y de objeto cercano, Arqueología del Paisaje.

\section{Introducción}

Khatm al Melaha es un emplazamiento arqueológico ubicado en Kalba (Khor Fakkan), Emirato de Sharjah, en la costa este de los Emiratos Árabes Unidos (Fig. 1). Se trata de una pequeña y redondeada colina que apenas se eleva 27 metros sobre el nivel del mar, pero su posición en el territorio y su ubicación solitaria en la desembocadura de un wadi, la convierte en un espacio excepcional, cuya característica más destacable es una potente visibilidad. Cuando se visita, y posteriormente se va trabajando con este yacimiento, se comprueba que durante miles de años el sitio poseyó una indudable finalidad simbólica.

La línea de costa, hoy alejada algo más de un kilómetro, se encontraba a los pies de la colina en el período en que fueron realizados los grabados que constituyen la base de nuestro trabajo de investigación. Los concheros en la base de la misma, cuya datación más antigua se retrotrae al $\mathrm{V}$ milenio a.C., y su reutilización datada ya en períodos consecutivos pertenecientes a la Edad del Bronce y a la Edad del Hierro, atestiguan, aparte de otras evidencias, el uso continuado que se confirió a este lugar durante todo un amplísimo período temporal.

Los planteamientos metodológicos que nos propusimos para abordar el estudio de los petroglifos son, por una parte, a nivel teórico, el empleo de los métodos de trabajo de la Arqueología del Paisaje y por otra, y a nivel técnico, la utilización de las nuevas tecnologías de fotogrametría digital y escaneado láser como recurso óptimo para el registro, documentación, procesamiento y

`Corresponding Author: Xosefina Otero, artabria@gmail.com 
posterior divulgación de los resultados (Farjas et al. 2010).

La gran mayoría de los petroglifos localizados en Khatm al Melaha, se encuentran en la ladera orientada al este. Por tanto, en los diferentes períodos en que fueron realizados los grabados, estos serían también visibles, o al menos localizables, desde el mar, algo que se repite en petroglifos ubicados en zonas costeras de Europa.

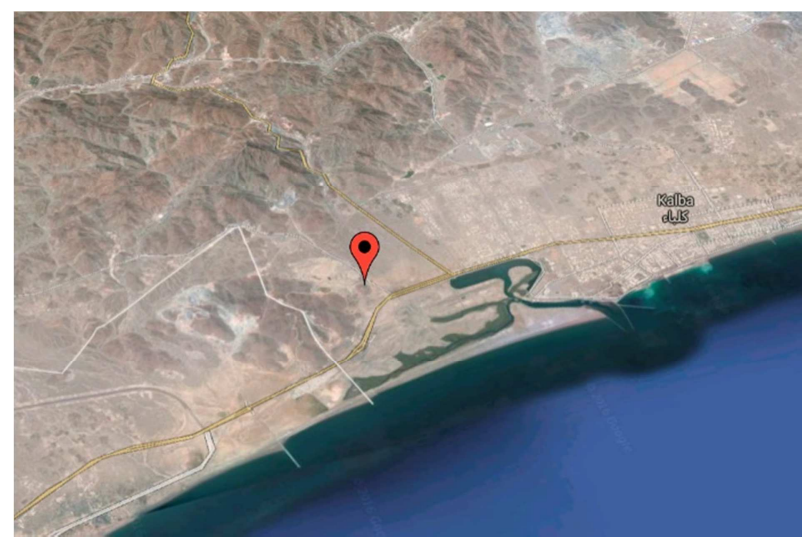

Figura 1: Emplazamiento de Khatm al Melaha (Google).

En la última campaña, en noviembre de 2016 , realizamos una prospección visual de la siguiente ladera orientada al este, pues la colina tiene dos tramos, uno primero coronado por un enterramiento, que ha sido datado en la Edad del Bronce Temprana, a finales del IV milenio o principios del III a.C., y que forma parte de un conjunto de tumbas del mismo período que jalonan toda la vertiente de una pequeña cordillera al sur de la colina que limita con el Sultanato de Omán.

En esta zona de la península arábiga, son numerosos este tipo de enterramientos que suelen ubicarse en las cimas de las montañas a lo largo de crestas prominentes y muy visibles (Dood and Dueñas 2014).

Los resultados de esta prospección fueron, en principio, estériles, puesto que no encontramos grabados en este segundo tramo de la colina, pero sería recomendable realizar una nueva prospección en detalle, pues en la cima se localizan un mayor número de enterramientos, y posee una perfecta visibilidad de $360^{\circ}$ sobre todo el territorio.

Sabemos que los petroglifos servían como "mensajes" entre grupos y personas que no estaban presentes simultáneamente, así pues, los destinatarios de dichos mensajes deberían ser capaces de localizar los petroglifos (Bradley et al. 1994) y de ese modo descifrar o interpretar el significado de dichos códigos.

Si no había escritura en esos períodos culturales, es lógico pensar que las representaciones, tanto pictóricas como de grabados en soporte pétreo, deberían cumplir una función narrativa entendible por los individuos de esas sociedades. Es muy difícil interpretarlos porque nuestro pensamiento simbólico se ha transformado radicalmente, pero parece obvio que debían ser algo más que una expresión puramente artística.

\section{El arte rupestre de Khatm al Melaha}

Los grabados de Khatm al Melaha fueron trazados en la superficie de fragmentos de roca serpentina, del complejo ofiolítico Semail, que se generó cuando la placa Saudí se introdujo bajo el sistema Irán-Zagros, durante el Cretácico.

Hay localizados, en la colina, más de un centenar de paneles. Estos se encuentran esparcidos en la ladera este, a partir de unos metros de la base y hasta la cima de la misma (Fig. 2).

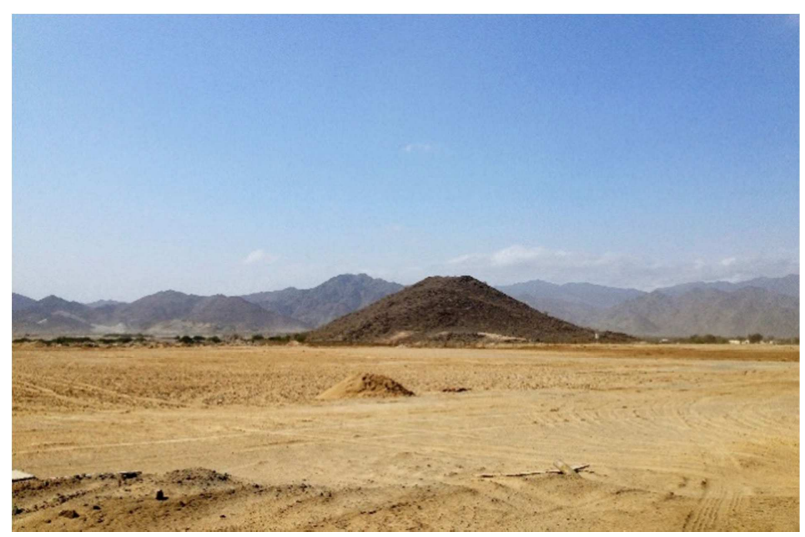

Figura 2: Vista de la ladera Este, donde se ubican los petroglifos.

En la investigación actual ya no hay ninguna duda que "la localización de los petroglifos está determinada por patrones regulares de emplazamiento y relación con el entorno vinculados al uso y aprovechamiento de esos espacios" (Criado et al. 2013) y a pesar de las enormes diferencias medioambientales entre la localización de éstos y los que, simultáneamente, se estaban produciendo en otros puntos del planeta, incluso a miles de kilómetros, las características son peculiarmente comunes.

Esto nos ha llevado a formular una de las cuestiones fundamentales de la presente investigación: ¿por qué en espacios tan alejados y ambientalmente diferentes, se estaban produciendo manifestaciones representativas de la relación y utilización del paisaje tan similares? Las superficies y alturas escogidas para realizar las representaciones de Khatm el Melaha, las técnicas empleadas, los motivos representados, nos trasladan, inevitablemente, a otras representaciones de Europa y África del mismo período (Fig. 3).

En este marco científico, nuestro trabajo se centra en la utilización de técnicas de medición avanzadas que permitan obtener una reconstrucción virtual del emplazamiento y encajarlo en su paisaje original (Santos 1998), reproduciendo las condiciones ambientales en las que vivían los autores de los petroglifos y sus comunidades; asi como facilitar el estudio de los detalles de los mismos, haciendo posible analizar e interpretar cómo fueron realizados, qué motivos eran los más utilizados, su potencia simbólica y ritual, y llegar a poder analizar estudios comparados con petroglifos llevados a cabo por culturas coetáneas en territorios muy alejados de nuestra zona de estudio.

De entre los más de cien paneles, seleccionamos 22 para su reproducción fotogramétrica por el interés 
iconográfico que presentaban con respecto a los propósitos de nuestro proyecto.

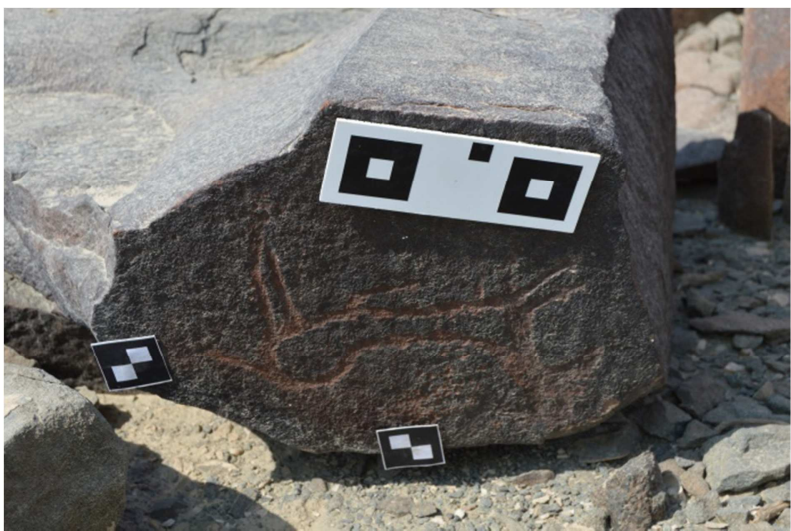

Figura 3: Panel con representación de un cérvido y técnica de abrasión.

En los motivos de los grabados del Bronce, con una datación aproximada del 2000 a.C., predominan cuadrúpedos característicos de la zona: oryx, ibex, y otros ungulados, así como otros motivos diferenciados, como el que pensamos podría ser una embarcación, o una representación humana con círculos concéntricos centrales.

Encontramos paneles de manadas (Fig. 4), hembras con crías en actitud relajada, sin gestos de tensión de caza, y con evidentes esfuerzos, por parte del autor o autores de los mismos, por intentar representar diferentes perspectivas, y otros paneles, de menor tamaño, con individuos sueltos, tanto machos como hembras.

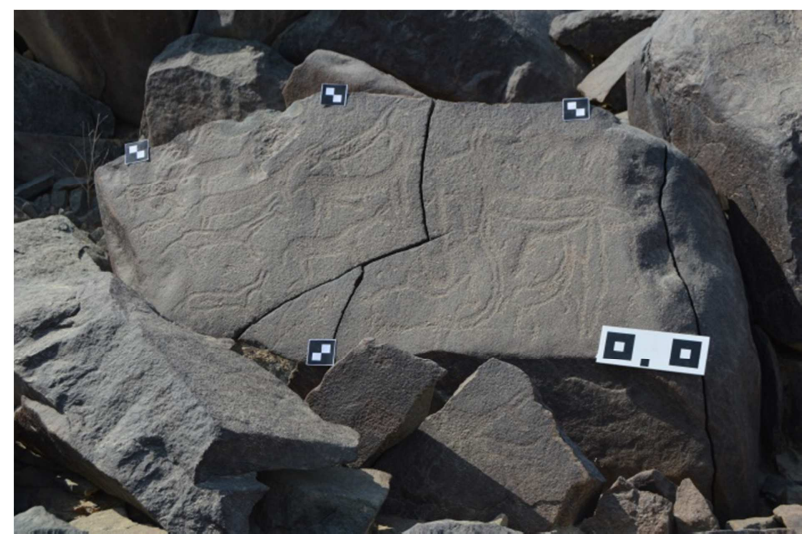

Figura 4: Panel con una manada de cérvidos y técnica de piqueteado.

Otro capítulo muy interesante, también con técnica de piqueteado, estaría compuesto por las representaciones esquemáticas de formas sinuosas, círculos concéntricos asociados a una representación humana y diseños de "rectángulos con esquinas redondeadas y segmentados en el interior por diámetros horizontales y verticales" (Santos 2007) que deseamos estudiar en la próxima campaña pues encontramos marcados paralelismos con representaciones similares al Esquemático Atlántico del noroeste peninsular.

En cuanto a las representaciones de la Edad del Hierro, tal como señala Santos (2007) para el Arte Rupestre Atlántico de la misma época, observamos que los paneles parecen representar la preponderancia de la sociedad humana sobre la naturaleza, expresada a través del dominio de los humanos sobre los animales.

Vemos paneles con escenas en las que dicho dominio queda patente a través de determinados rituales que conocemos de prácticas recogidas en estudios sobre el mundo mágico-religioso de culturas europeas antiguas (Santos 2004). La técnica empleada para la realización de estas figuras es por abrasión, muy probablemente realizada con un objeto pétreo (Fig. 5).

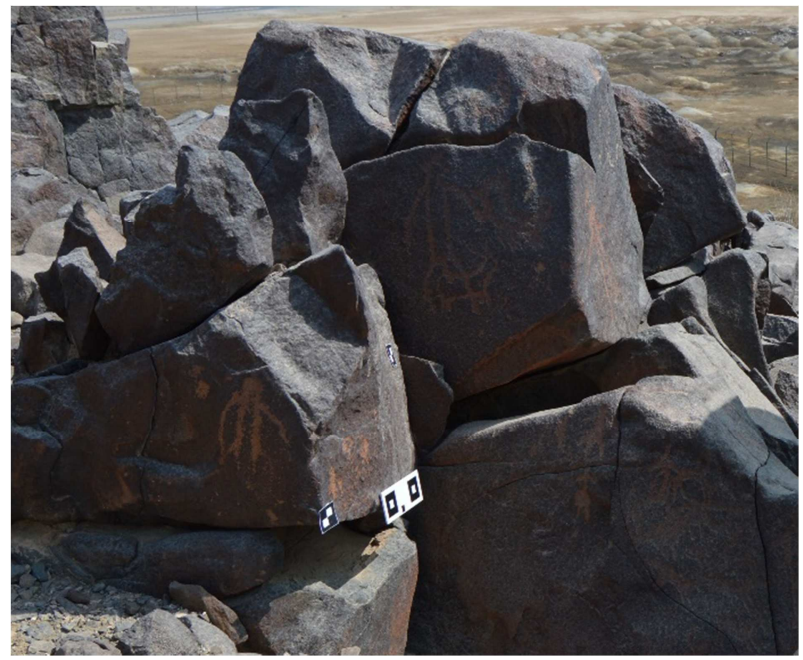

Figura 5: Paneles con escenas simbólico-mágicas y técnica de abrasión.

En relación a esto, podemos mencionar otras zonas próximas al yacimiento de Khatm al Melaha, con abundante arte rupestre coetáneo, como el sitio arqueológico de Wadi Halo (Fig. 6), en el mismo Emirato de Sharjah, en dónde nos volvemos a encontrar escenas muy parecidas, y con varias representaciones de jinetes, que nos están arrojando una cronología que no podría ser anterior al siglo IX a.C., cuando se produjo la domesticación de los caballos.

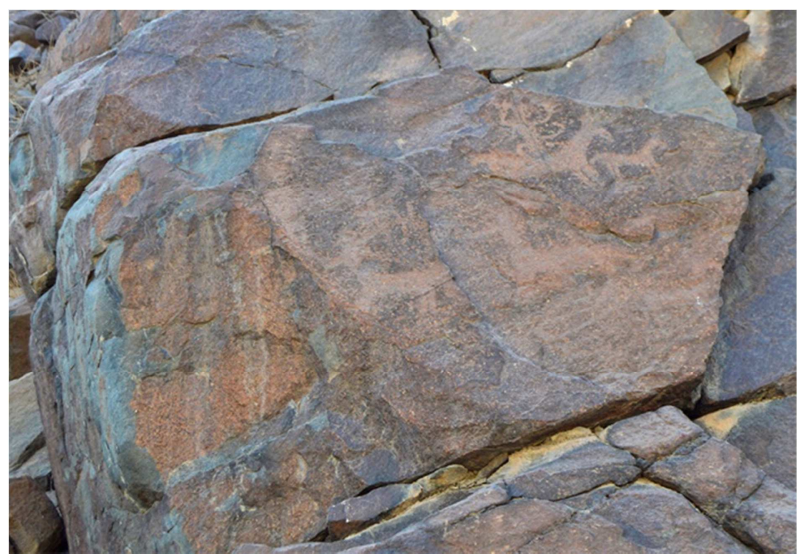

Figura 6: Paneles con escenas de jinetes en Wadi Halo.

A lo largo de la Prehistoria Reciente y la Protohistoria, las comunidades humanas, en áreas geográficas tan distantes, tales como la Península Arábiga, que es la que nos ocupa en la actualidad, y Europa Occidental, se expresaban, través del arte rupestre, con iconografías muy semejantes. Dichas semejanzas podrían ser explicadas por los contactos a larga distancia entre 
ambas zonas, especialmente intensos a partir de la innovación de la metalurgia, industria que demanda redes de intercambio para conseguir materias primas que no se encuentran distribuidas de forma regular (Kristiansen and Larsson 2005).

Hay estudios precedentes, en este sentido, que se han centrado fundamentalmente en Europa y su entorno cercano, sin embargo, nosotros consideramos que sería interesante buscar evidencias de que dichas redes se extendían también hasta áreas geográficas mucho más alejadas. No obviamos, en ningún momento, que hay otras teorías sociológicas y antropológicas que dicen que "sociedades con un nivel de evolución semejante pudieron haber seguido estrategias semejantes para expresar su ideología", lo que favorecería, en su opinión, los parecidos iconográficos, aunque, en la nuestra, no los estilísticos.

Este artículo solo pretende ser un breve avance de los trabajos que queremos desarrollar en esta zona, tan desconocida para nuestro ámbito arqueológico. Los resultados de dichos trabajos creemos que pueden ser sumamente interesantes, sobre todo si tenemos en cuenta su riqueza y su carácter inédito.

\section{Fotogrametría digital: aérea, terrestre y de objeto cercano}

Para realizar nuestro trabajo de investigación sobre los petroglifos de Khatm al Melaha, con técnicas no invasivas y que nos proporcionase la mayor cantidad y calidad de información posible, nos decantamos por el empleo de las técnicas fotogramétricas, que nos permiten realizar todos los procesos con gran economía, tanto en tiempo como en recrsos (Rodriguez, 2014).

A partir de la captura de imágenes con una cámara digital, y el posterior tratamiento de las mismas con un software específico (Cabezos and Cisneros 2012), generamos una nube de puntos de los objetos, en nuestro caso cada uno de los paneles, que posteriormente nos permite realizar una malla densa y con la que obtenemos modelos 3D de cada uno de ellos y medidas de los mismos con una precisión adecuada para el estudio y para también poder actuar sobre las geometrías (Aparicio 2013).

En la campaña de noviembre de 2015, en Khtam al Melaha, además de realizar las tomas con una cámara digital Nikon D3200, con una resolución de 24 megapíxeles, que proporciona una calidad de imagen más que suficiente para realizar la fotogrametría de los paneles, se pudo emplear una nueva herramienta que nos permite la medición y modelado 3D en tiempo real mediante fotogrametría estereoscópica y escaneado por triangulación óptica.

Se trata de una tableta, denominada Tablet EyesMap, y que consiste en un dispositivo fabricado por la empresa española de tecnología e-Capture, ubicada en Mérida, Badajoz, que fue creada para llevar a cabo el desarrollo de este producto (Fig. 7).

El equipo EyesMap cuenta con un procesador Intel Core i7, de 16 gigas de RAM, y funciona sobre el sistema operativo Windows 8, muy fácil de usar una vez nos familiarizamos con su manejo. En la parte trasera de la tablet se ubican dos cámaras Sony de 13 megapíxeles, y un sensor de profundidad, así como sistemas GNSS e inerciales, que llevan a cabo la georreferenciación en tiempo real, otro avance considerable en economización de tiempo.

En cuanto a las capacidades de escaneo 3D de la tablet, se pueden digitalizar desde pequeños objetos a espacios interiores o exteriores, e incluso grandes construcciones. En la campaña de 2015, de Khatm al Melaha, fue utilizada en rangos de distancia medios y cortos.

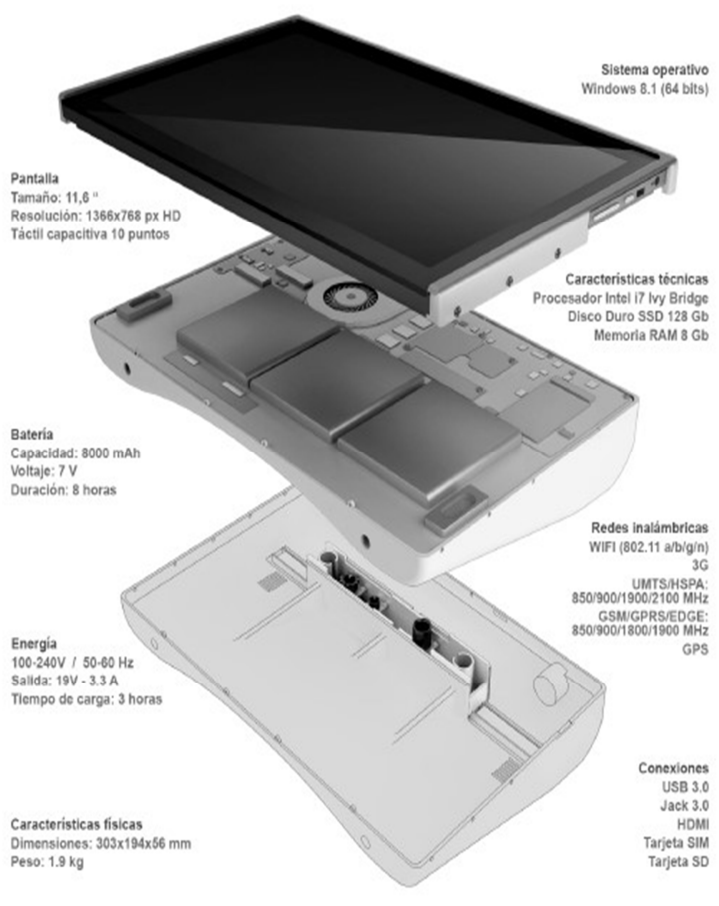

Figura 7: Especificaciones técnicas de la Tablet EyesMap (eCapture, 2016).

Cuando se inicia la aplicación EyesMap en la Tablet, se muestra el menú principal. Desde este menú se pueden seleccionar los distintos módulos, ocho en total:

- Los 3 primeros módulos están dedicados a la fotogrametría punto a punto, cuyo fin es la medición de coordenadas, distancias y superficies.

- Fotomodelado 3D: es el módulo a partir del cual se realizan modelos $3 \mathrm{D}$ con técnicas fotogramétricas utilizando las estéreo cámaras.

- Sensor de profundidad 3D: módulo de generación de una nube de puntos 3D utilizando el sensor de profundidad. Está indicado principalmente para zonas cercanas (máximo 4 metros) e interiores, y es especialmente útil en superficies homogéneas y sin texturas.

- Ortofotografía: generación de ortofotografías sobre las que se pueden realizar imágenes del objeto con una proyección ortogonal. Es muy útil para aplicaciones arquitectónicas y arqueológicas.

- GPS: este módulo permite el posicionamiento en coordenadas absolutas de la Tablet en 
tiempo real. También se pudo utilizar el módulo de post-proceso con el fin de mejorar las precisiones.

- Menú: este módulo permite gestionar proyectos, actualizar la aplicación, calibrar y orientar las cámaras

Para realizar el escalado de los modelos, usamos dianas estereoscópicas. En este proyecto se utiliza la de mayor tamaño, que tiene una longitud de $59 \mathrm{~cm}$. (Fig. 8), y que es adecuada para escalar objetos medianos y grandes. Para objetos pequeños puede utilizarse la diana de $15 \mathrm{~cm}$. Aunque no es necesario que aparezca la diana estereoscópica en todas las fotografías, es recomendable que se encuentre en el mayor número de imágenes para que el escalado sea más preciso. Este podría realizarse también manualmente.

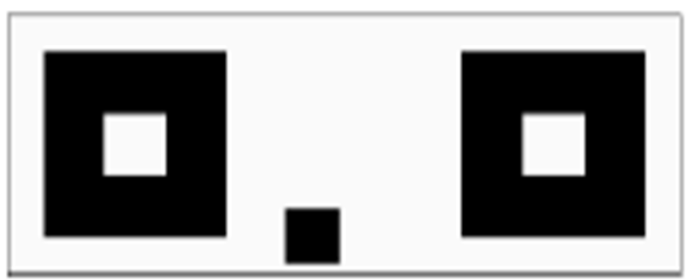

Figura 8: Diana estereoscópica utilizada.

Las dianas individuales pueden ser simétricas 0 asimétricas, y ambas se combinan con la finalidad de realizar la orientación automática en el módulo de fotogrametría, para realizar la orientación de las estéreo cámaras en el módulo "Orientación" y para realizar medidas de precisión en el módulo de fotogrametría punto a punto.

Los modelos obtenidos pueden ser georreferenciados a través del sistema GNSS en tiempo real con un error de $0,60 \mathrm{~m}$. Si deseamos mayor precisión, se pueden recoger datos durante 10 minutos para después postprocesarlos, obteniéndose un error de $0,10 \mathrm{~cm}$.

El sistema inercial integrado está compuesto por un giróscopo, un acelerómetro y un magnetómetro. Todo este sistema aporta información de velocidad, de la orientación de la tablet y de las fuerzas gravitacionales en tiempo real.

La tecnología fotogramétrica descrita, nos permitió obtener "in situ", y en pocos minutos, la geometría 3D de cada uno de estos paneles (Fig. 9), lo que nos facilitó, entre otras cosas, registrar con precisión los surcos de las superficies grabadas. Dicha precisión en el registro ha posibilitado también la identificación de, al menos, dos diferentes técnicas de grabado.

Es una figura barquiforme, que no habíamos detectado anteriormente como tal, la que nos llevará a uno de los ejes centrales de nuestro trabajo de investigación, pues si cuando a través del estudio fotogramétrico y la reconstrucción de la misma podemos concluir que se trata de una embarcación, debemos considerar la posibilidad de plantearnos si las representaciones que tenemos localizadas en el sureste de la península arábiga tenían relación con las encontradas en otros puntos del Mediterráneo y el Atlántico, si hubo influencias entre ellas a través de comunicación marítima y terrestre, o si, por el contrario, son fruto todas ellas de una casualidad evolutiva del pensamiento humano.

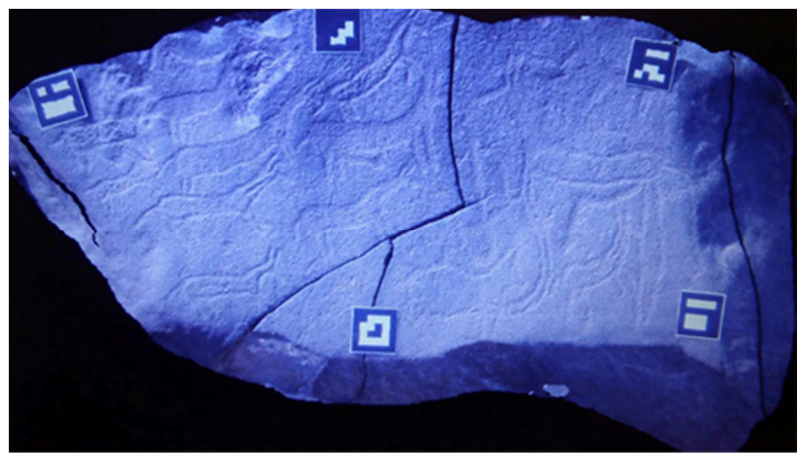

Figura 9: Geometría de uno de los paneles generada por la Tablet EyesMap en tiempo real.

En la última campaña, que se llevó a cabo en noviembre de 2016, para facilitarnos, precisamente, la identificación de relieves y marcas no visibles, probamos la aplicación DStretch. Se trata de un plugin creado por Jon Harman y cuyo principio operativo consiste en la intensificación del contraste de las variables cromáticas presentes en un archivo gráfico (Martínez et al. 2013), que hace posible ver detalles no captables a simple vista por nuestros ojos.

Aplicamos dicho plugin (Fig. 10), que está disponible en diferentes plataformas operativas, tanto en la obtención de nuevas imágenes de los petroglifos, como en el tratamiento de las que ya teníamos de otras campañas anteriores, y los resultados han sido francamente increíbles, pues a través de los diferentes filtros de color y con fotos obtenidas, tanto con cámara digital como con un smartphone, se hacían visibles detalles que no eran apreciables en tomas anteriores, aunque se hubiesen llevado a cabo en las mejores condiciones posibles (Fig. 11)

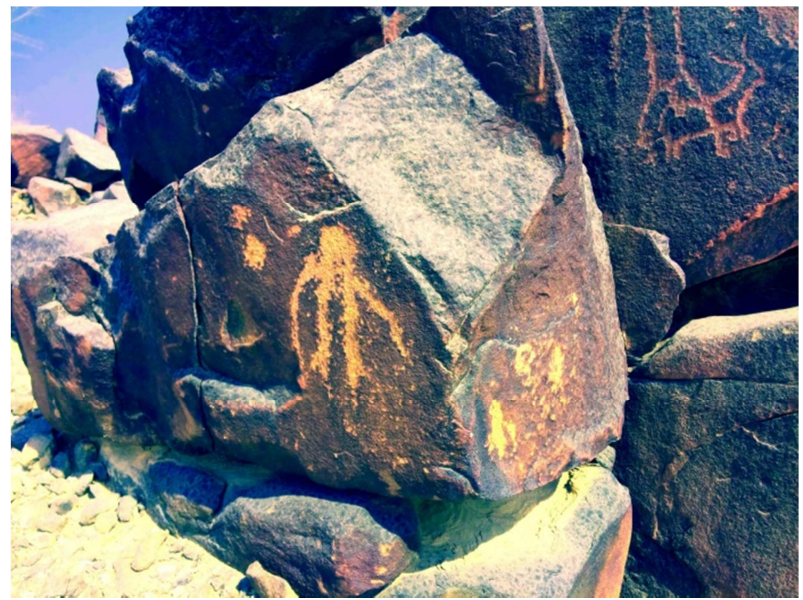

Figura 10: Filtro de la app dStretch for Android aplicado a los grabados de uno de los paneles.

En esta última intervención, de noviembre de 2016, en Khatm al Melaha, contamos con la inestimable colaboración de Jorge Angás, director de 3Dscanner Technologies http://3dscanner.es/, una empresa Spin-off de la Universidad de Zaragoza, que lleva a cabo proyectos de ingeniería y patrimonio (Angás 2012), y pudimos disponer de su magnífico trabajo con un drone sensefly eBee, drone de ala fija ultraligero, que obtiene 
imágenes RGB que al ser procesadas por el propio sistema operativo realiza ortofotos y mapeado 3D (Fig. 12).

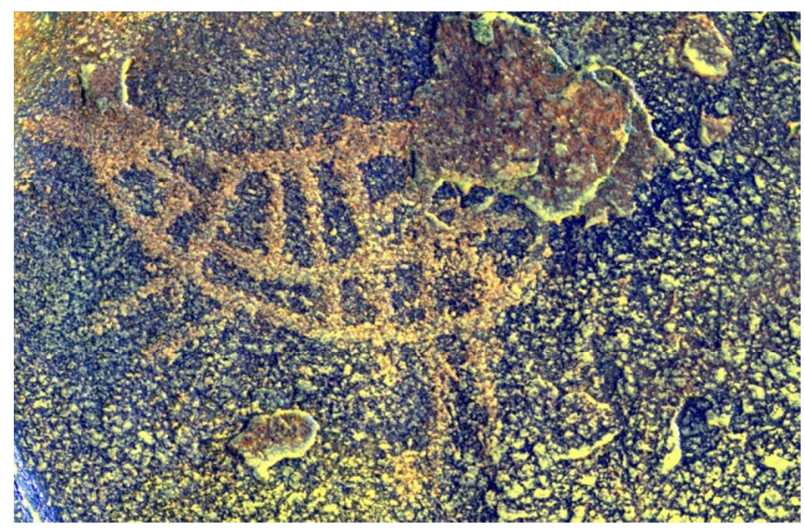

Figura 11: DStretch for Android aplicado en el posible barquiforme.

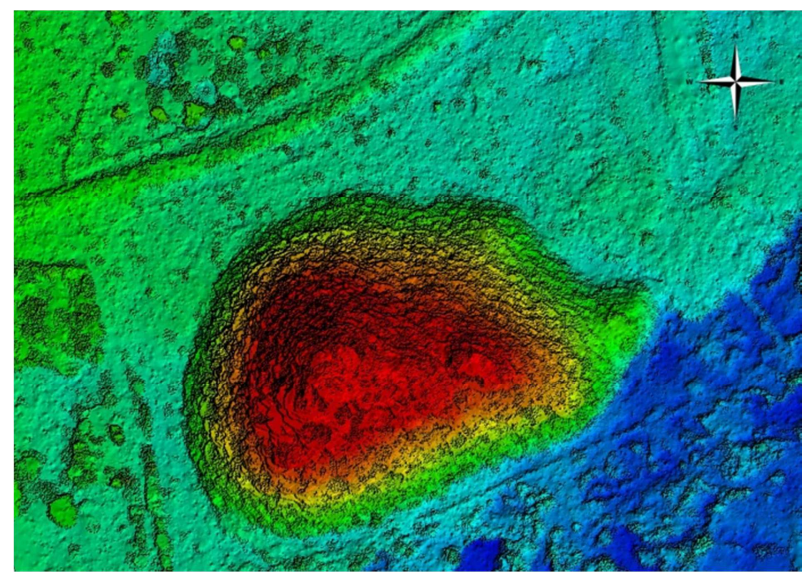

Figura 12: Modelo digital de superficie realizado con un drone Sensefly eBee por Jorge Angás.

La fotogrametría digital aérea y el modelo digital de superficie (MDS), que se realiza actualmente en gran parte de los sitios arqueológicos en proceso de investigación, se han convertido, en estos últimos años, en herramientas básicas en el desarrollo del trabajo de documentación arqueológica, tanto por la precisión y calidad de la información que se obtiene, como por la perspectiva que nos ofrece en la interpretación del territorio desde el estudio a través de la Arqueología del Paisaje.

La importancia nuestro trabajo radica, por un lado, en la posibilidad de investigar en una zona arqueológica inédita, y por otro, en la cantidad y calidad de la información que nos aportan los petroglifos de Khatm al Melaha, con una proyección simbólica que nos pone en contacto con el arte rupestre mediterráneo y europeo, lo que nos plantea la posibilidad del establecimiento de contactos entre ambas zonas $\mathrm{o}$, por el contrario, un desarrollo del pensamiento autónomo y coetáneo.

\section{Conclusiones}

Nuestros principales objetivos, con el trabajo que llevamos a cabo en Khatm al Melaha, es dar a conocer esta zona arqueológica inédita y llevar a cabo su documentación implementando una tecnología concreta con base fotogramétrica y de escaneado 3D.

En una primera fase, de toma de datos, se realizó una inspección visual de la zona y se seleccionaron 22 paneles de petroglifos, tanto por su interés iconográfico como por sus características morfológicas, realizando un ensayo de captura de datos para su modelado 2D y $3 D$ con el nuevo equipo EyesMap. En una segunda fase se realizó un mapeado 3D con un drone de alafija y se utilizó la app dStrecht para mejorar la visualización de elementos no visibles en los grabados. Y, como paso ulterior, será llevado a cabo un estudio más detallado desde la óptica de la Arqueología del Paisaje (Criado 2012), abordando, desde dicho marco teórico, su emplazamiento, iconografía y contexto histórico.

\section{Agradecimientos}

Este trabajo es posible gracias a la colaboración con Sharjah Archaelogy Authority, del Emirato de Sharjah, Emiratos Árabes Unidos.

Se realiza dentro de los proyectos:

\section{- HAR2015-65649-C2-2-P(MINECO/FEDER) \\ - $\quad$ S2015/HUM-3377(CAM/FEDER)}

\section{References}

ANGÁS PAJAS, J., 2012. Nuevas técnicas de documentación geométrica y análisis del arte rupestre. Jornadas técnicas para la gestión del arte rupestre, patrimonio mundial. (Alquezar, Huesca, 2012), pp. 61-72 https://www.academia.edu/7530177/Nuevas_t\%C3\%A9cnicas_de_documentaci\%C3\%B3n_geom\%C3\%A9trica_y_a n\%C3\%A1lisis_del_arte_rupestre [5/05,2017].

APARICIO RESCO, P., 2013. Arqueología virtual para la documentación, análisis y divulgación del patrimonio: el horno de cal de Montesa (Valencia). Available: http://www.editarx.es/cat\%C3\%A1logo-delibros/monograf\%C3\%ADas/arqvir-detail [5/28, 2016].

BRADLEY, R., CRIADO BOADO, F., FÁBREGAS, R. (1994). "Los petroglifos como forma de apropiación del espacio: algunos ejemplos gallegos. Trabajos de Prehistoria, 51(2)", pp. 159-168. Disponible: https://www.academia.edu/2295429 [5/28, 2016].

CABEZOS BERNAL, P.M. and CISNEROS VIVÓ, J.J., 2012. Fotogrametría con cámaras digitales convencionales y software libre. Available: http://dx.doi.org/10.4995/ega.2012.1407 [5/28, 2016].

CRIADO BOADO, F., 2012. Arqueológicas. La Razón Perdida. Barcelona: Bellaterra. Available: http://www.arqueologicas.com/ [5/28, 2016]. 
CRIADO BOADO, F, MARTÍNEZ CORTIZAS, A. and GARCÍA QUINTELA, M.V., 2013. Petroglifos, paleoambiente y paisaje: estudios interdisciplinares del arte rupestre de Campo Lameiro (Pontevedra). TAPA-INCIPIT. Available: http://libros.csic.es/product_info.php?products_id=640 [5/28, 2016].

DOOD, J. and DUEÑAS GARCÍA, M.DJ., 2014. New discoveries, new directions: Rock art research on Bornholm $2013-$ 2014.Adoranten, 112-22. Available: http://search.proquest.com/openview/d76fb6e2ac69ee9a7f0011a7944136bb/ 1 ?pq-origsite=gscholar\&cbl=2032487 [5/28, 2016].

E-CAPTURE, 2016. Especificaciones técnicas de la Tablet EyesMap: Manual de usuario EyesMap. Available: http://ecapture.es [4/14, 2016].

FARJAS, M., N. QUESADA, M. ALONSO, A. DIEZ and CARPA 2010. New Technologies Applied to Artefacts: Seeking the Representation of a Column's Capital, in: Nicolucci, F. and S. Hermon (eds.), Beyond the Artifact. Digital Interpretation of the Past. Proceedings of CAA2004, Prato 13-17 April 2004. Archaeolingua, Budapest, pp. 21-27.

KRISTIANSEN, K., LARSSON, T.B., 2005. La Emergencia de la sociedad del Bronce. Viajes, transmisiones y transformaciones. Bellaterra: Barcelona. Available: http://www.ed-bellaterra.com/php/llibreslnfo.php?idLlibre=292 $[5 / 28,2016]$.

MARTÍNEZ COLLADO, F.J., MEDINA RUÍZ, A.J., and SAN NICOLÁS DEL TORO, M., 2013. Aplicación del plugin DStretch para el programa ImageJ al estudio de las manifestaciones pictóricas del abrigo Riquelme (Murcia). Cuadernos de Arte Rupestre, Revista Digital. Available: http://carmesi2.regmurcia.com/recursos/arterupestre/6/MartinezCAR201306_13.pdf [17/6, 2017].

RODRÍGUEZ LÓPEZ, F.I., 2014. Representación 3D de petroglifos: propuesta de metodología de modelización de los grabados del Valle de Tamanart, Marruecos. Trabajo Fin de Máster, 2014. Universidad Politécnica de Madrid. Available:http://oa.upm.es/30703/ [5/28, 2016].

SANTOS ESTÉVEZ, M., 1998. Los espacios del arte: El diseño del panel y la articulación del paisaje en el arte rupestre gallego. Trabajos de Prehistoria. 55(2): 73-88. Available: http://hdl.handle.net/10261/6752 [5/28, 2016].

SANTOS ESTÉVEZ, M., 2004. Arte rupestre, estilo y construcción social del espacio en el Noroeste de la Península Ibérica. Tesis doctoral.

SANTOS ESTÉVEZ, M., 2007. Petroglifos y paisaje social en la prehistoria reciente del noroeste de la península ibérica. Traballos de Arqueoloxía e Paisaxe. Traballos de Arqueoloxía e Patrimonio, 38: 220. Available: http://hdl.handle.net/10261/37908 [5/28, 2016]. 